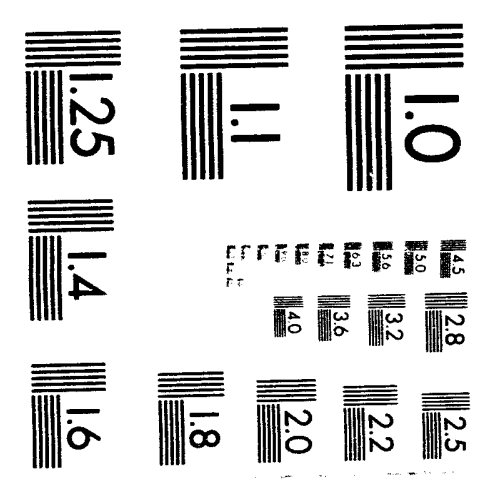



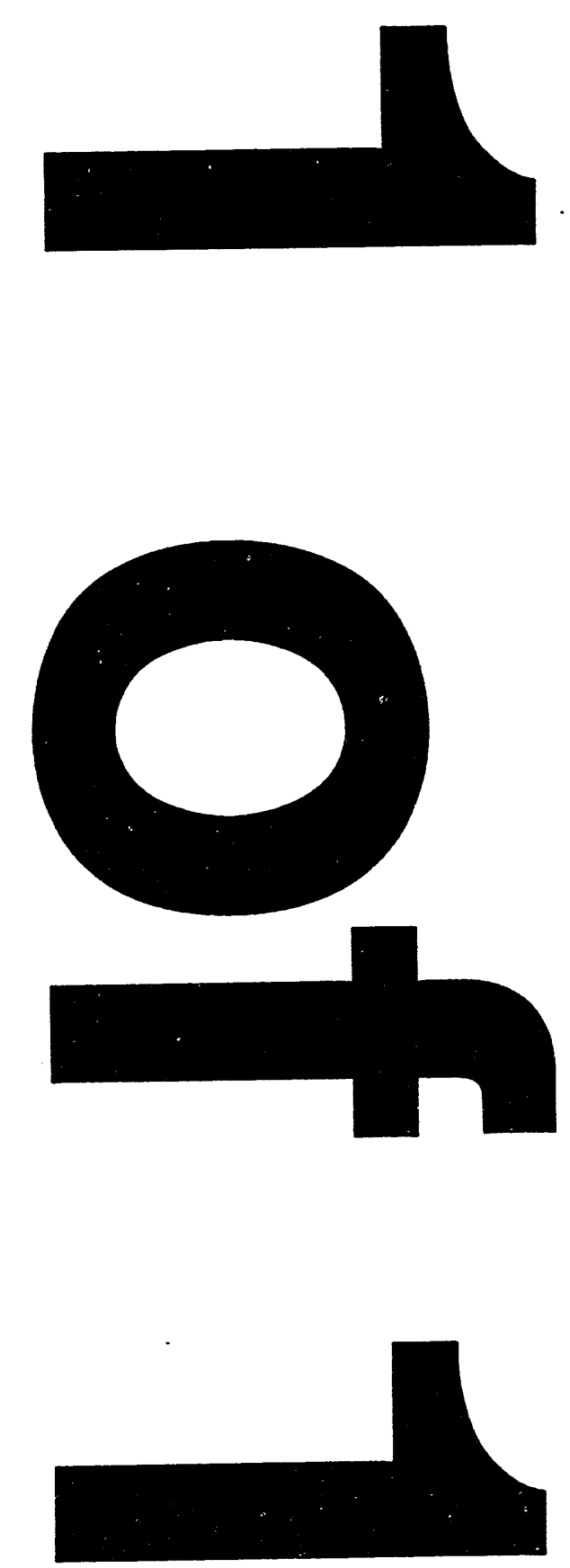


\section{AMKNER/CP- 80342 Conf- $940115--17$}

DRY DEPOSITION OF PAN TO GRASSLAND VEGETATION

P. V. Doskey, M. L. Wesely, D. R. Cook, and W. Gao

Environmental Research Division

Argonne National Laboratory

Argonne, IL 60439

\section{DISCLAIMER}

This report was prepared as an account of work sponsored by an agency of the United States Government. Neither the United States Government nor any agency thereof, nor any of their employees, makes any warranty, express or implied, or assumes any legal liability or responsibility for the accuracy, completeness, or usefulness of any information, apparatus, product, or process disclosed, or represents that its use would not infringe privately owned rights. Reference herein to any specific commercial product, process, or service by trade name, trademark, manufacturer, or otherwise does not necessarily constitute or imply its endorsement, recommendation, or favoring by the United States Government or any agency thereof. The views and opinions of authors expressed herein do not necessarily state or reflect those of the United States Government or any agency thereof.

For

Conference on Atmospheric Chemistry 23-28 January 1994, Nashville, Tennessee

This work was supported by the U.S. Department of Energy, Office of Energy Research, Office of Health and Environmental Research, under contract W-31-109-Eng-38.

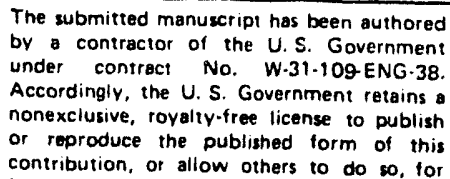




\title{
DRY DEPOSITION OF PAN TO GRASSLAND VEGETATION
}

\author{
P. V. Doskey, M. L. Wesely, D. R. Cook, and W. Gao \\ Environmental Research Division \\ Argonne National Laboratory \\ Argonne, Illinois
}

\section{INTRODUCTION}

Peroxyacetyl nitrate or PAN $\left(\mathrm{CH}_{3} \mathrm{C}(\mathrm{O}) \mathrm{OONO}_{2}\right)$ is formed in the lower troposphere via photochemical reactions involving nitrogen oxides $\left(\mathrm{NO}_{x}\right)$ and nonmethane hydrocarbons (NMHCs). PAN, an important reservoir of reactive nitrogen, exists in an equilibrium with $\mathrm{NO}_{2}$ and is greatly affected by small changes in temperature (e.g., Singh, 1987). When this photochemical oxidant enters the relatively cool upper troposphere, its stability contributes to long-range transport. In remote regions it can return to the warmer lower troposphere, where it thermally degrades (releasing $\mathrm{NO}_{2}$ ) and contributes to the formation of $\mathrm{O}_{3}$. PAN has a lifetime in the free troposphere of about three months and is removed by photolysis or reaction with $\mathrm{OH}$. Dry deposition will decrease its lifetime, although the few measurements that have been made indicate that this process is slow. Measurements of the uptake of PAN by alfalfa in growth chambers indicated that the dry deposition velocity (downward flux divided by concentration at a specified height) was $0.75 \mathrm{~cm}$ $\mathrm{s}^{-1}$ (Hill, 1971). Garland and Penkett (1976) measured a dry deposition velocity of $0.25 \mathrm{~cm} \mathrm{~s}^{-1}$ for PAN to grass and soil in a return-flow wind tunnel. Shepson et al. (1992) analyzed trends of PAN and $\mathrm{O}_{3}$ concentrations in the stable nocturnal boundary layer over mixed deciduous/coniferous forests at night, when leaf stomata were closed, and concluded that the deposition velocity for PAN was at least $0.5 \mathrm{~cm} \mathrm{~s}^{-1}$.

We measured the dry deposition velocity of PAN to a grassland site in the midwestern United States with a modified Bowen ratio technique (e.g., Wesely et al., 1989). Experiments were conducted on selected days during September, October, and November of

Corresponding author address: Paul V. Doskey, Environmental Research Division, Argonne National Laboratory, Argonne, IL 60439.
1990. An energy balance Bowen ratio station was used to observe the differences in air temperature and water vapor content between heights of 3.0 and $0.92 \mathrm{~m}$ and to evaluate the surface energy balance. Air samples collected at the same two heights in Teflon bags were analyzed for PAN by a gas chromatographic technique. We present an example of the variations of PAN concentrations and gradients observed during the day and compare measurements of the dry deposition velocity to expectations based on the physicochemical properties of PAN.

\section{EXPERIMENTAL ASPECTS}

The experiments were performed at the Argonne meteorological research site, which occupies an area $300 \mathrm{~m}$ by $400 \mathrm{~m}$ covered by herbaceous vegetation in the southwest corner of Argonne National Laboratory. The vegetation includes grasses such as Indiangrass (Sorghastrum nutans), big bluestem (Andropogon gerardii), and broadleaf plants, primarily wild parsnip (Pastinaca sativa), gray dogwood (Cornus racemosa), tall goldenrod (Solidago altissima), and wild strawberry (Fragaria virginiana).

An energy balance Bowen ratio station was used to measure gradients of temperature and water vapor pressure in concert with routine measurements of wind speed, wind direction, net radiation, soil temperature, and soil heat flux. The gradient system employed platinum resistance elements, one for the dry- and one for the wet-bulb temperature measurement at each of two levels. The aspirated shields for the resistance elements, which were located at $0.92 \mathrm{~m}$ and $3.0 \mathrm{~m}$ to give a separation of $2.08 \mathrm{~m}$, were automatically exchanged every $15 \mathrm{~min}$ via a motorized belt system. This exchange allowed offsets to be eliminated in the analysis. All of the instruments except the soil heat flux sensors were calibrated before and after the investigation. The soil heat flux was measured with a set of three heat flux plates located $10 \mathrm{~cm}$ below the surface. The resulting estimate was 
adjusted for soil heat storage above the plates by using observations from a set of three soil temperature sensors, each of which integrated the temperature from $10 \mathrm{~cm}$ to the surface. Among the quantities calculated were latent heat flux $(\lambda E)$ and sensible heat flux $(H)$.

Several observations and calculations were made of important micrometeorological parameters. Solar irradiances were measured with a nearby pyranometer. Friction velocities $\left(u_{*}\right)$ were estimated via a bulk aerodynamic technique involving iterative calculations based on the locally measured mean wind speed and stability adjustments made with the Bowen ratio station's estimates of $\mathrm{H}$ and $\lambda \mathrm{E}$. Estimates of the local aerodynamic surface temperature were extrapolated from air temperatures by using fluxgradient relationships (e.g., Brutsaert, 1982).

Samples for PAN analysis were collected simultaneously at 0.92 and $3.0 \mathrm{~m}$ above the surface from a tower adjacent to the Bowen ratio apparatus. The sampling interval was $30 \mathrm{~min}$. The samples were collected in Teflon ${ }^{\circledR}$ FEP bags with Teflon ${ }^{8}$ TFE low-flow diaphragm pumps. All connections were made with Teflon ${ }^{\circledR}$ PFA fittings and tubing. To prevent thermal decomposition of PAN during sample collection, the pumps were operated at the lowest possible speed to minimize heating of the pump head. The pump speed was controlled with a manual speed controller to produce a flow rate of about $70 \mathrm{~mL} \min ^{-1}$. Measurements at this speed indicated that the pump exhaust temperature was equal to the ambient air temperature.

PAN was measured immediately after collection by withdrawing $5 \mathrm{~mL}$ of air from the Teflon ${ }^{\circledR}$ bags with a glass, gas-tight syringe and directly injecting the sample into a gas chromatograph equipped with an electron capture detector (e.g., Gaffney et al., 1989). PAN was separated on 10\% Carbowax 400 on Supelcoport $\left(60 / 80\right.$ mesh) packed into Teflon ${ }^{\circledR}$ PFA tubing ( $100 \mathrm{~cm} \times 0.318 \mathrm{~cm}$ ID). The flow rate of $\mathrm{N}_{2}$ through the column was $30 \mathrm{~mL} \mathrm{~min}^{-1}$. Oven and detector temperatures were maintained at $30^{\circ} \mathrm{C}$ and $40^{\circ} \mathrm{C}$, respectively. Under these conditions PAN eluted at $3 \mathrm{~min}$ and water at $12 \mathrm{~min}$, so that injections could be made every $15 \mathrm{~min}$. Bags were cleaned by filling them with $\mathrm{N}_{2}$ and evacuating with a Teflon ${ }^{\circledR}$ diaphragm vacuum pump a total of three times.

The reproducibility of the PAN measurements was determined by sampling with the two pumps at the same height. Eight trials indicated that the precision was $\pm 3.6 \%$, which represents plus or minus one standard deviation. Therefore, we could be confident in gradients in concentration that were greater than $7.2 \%$.

The dry deposition rate (FPAN) of PAN was estimated with the modified Bowen ratio technique as follows:

FPAN $=H\left(\rho c_{p}\right)^{-1} \Delta[P A N] / \Delta T$

Here $\rho$ is the air density, $c_{p}$ is the specific heat capacity of air at constant pressure, and $\Delta$ signifies the difference between the lower and upper observations. The deposition velocity $\left(v_{d}\right)$ was found as

$v_{\mathrm{d}}=-\mathrm{FPAN}_{\mathrm{P}} /[\mathrm{PAN}]$

where the measurement of the mean [PAN] at a height of $3 \mathrm{~m}$ was used.

\section{RESULTS AND DISCUSSION}

Concentrations of PAN were found to increase to maximum levels in the mid afternoon and to decrease toward the evening hours (Figure 1). This profile is typical of atmospheric species like PAN that are formed via photochemical reactions. The decreasing PAN concentrations during the late afternoon are attributed to thermal decomposition.

The gradient of PAN concentrations at the two heights was found to increase toward mid afternoon to maximum levels and then to decrease afterward until the late afternoon (Figure 1). This behavior mirrored the concentration profile. The large gradient in mid afternoon when vertical mixing is strong, as indicated by the large values of $u_{*}$ (Figure 1 ), is attributed to large rates of deposition. Toward the evening hours the gradient in concentration tended to increase as vertical mixing became very weak.

Table 1 summarizes the results of the experiments. Considerable variability in the estimates of FPAN and thus $v_{d}$ for PAN was introduced by the limited precision of the [PAN] measurements. For example, flux-gradient formulas can be manipulated to show that the difference in concentration measured across a twofold change in height is usually in the range of $1-9 \%$ for a deposition velocity of $0.5 \mathrm{~cm} \mathrm{~s}^{-1}$ in typical daytime conditions (e.g., Wesely et al., 1989). Because the change in heights relative to 

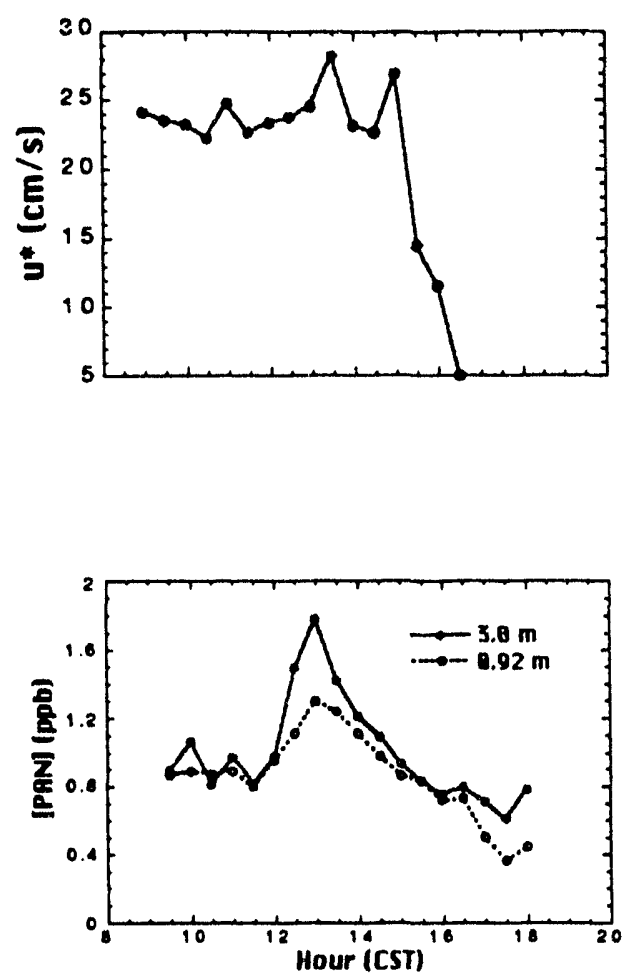

Figure 1. Estimates of friction velocity (upper panel) and measurements of [PAN] (lower panel) at the two heights indicated.

the aerodynamic displacement height of the local vegetation during the field experiments represented approximately an eightfold change, we could expect perhaps a $10-70 \%$ difference in the concentration measurements at the two heights if the deposition velocity was near $0.5 \mathrm{~cm} \mathrm{~s}^{-1}$. In comparison, the precision of each sample measurement was approximately $\pm 3.6 \%$, which implies that the range of differences is approximately $\pm 20 \%$ for a $95 \%$ confidence level. Hence, each estimate of $v_{d}$ could be in error by \pm 0.15 to $\pm 2.0 \mathrm{~cm} \mathrm{~s}^{-1}$, depending on atmospheric conditions. The least reliable results would be produced in very windy or very unstable atmospheric conditions.

Because of the variability introduced by the [PAN] measurements, several half-hours of flux data were averaged to produce the data presented in Table 1 . The choice of which periods to average was based primarily on the need to have fairly steady winds and solar radiation during the averaging period. Because the data can be manipulated to show different trends depending on which half-hours of data are averaged, the conclusions in this paper should be considered tentative.

The values shown in Table 1 for aerodynamic resistance $\left(R_{a}\right)$, quasilaminar boundary layer resistance $\left(R_{b}\right)$ for PAN, and bulk canopy resistance $\left(R_{c}\right)$ for PAN were computed on the basis of rather standard formulations (e.g., Wesely and Hicks, 1976; Garland, 1977). Values of $R_{c}$ for water vapor are also shown to indicate the level of stomatal control on air-surface exchange. That is, if water vapor and PAN transfer were entirely controlled by exchange through the stomata via the same pathways within the substomatal cavities, then $R_{c}$ for PAN would be approximately 2.6 times the value of $R_{c}$ for $\mathrm{H}_{2} \mathrm{O}$, because this value is roughly the ratio of their molecular diffusivities in air. Although $R_{c}$ for $\mathrm{H}_{2} \mathrm{O}$ is too small to represent only stomatal exchange because of evaporation occurring at the soil surface beneath the canopy, the value of $R_{c}$ for PAN is of the same order as the value for $\mathrm{H}_{2} \mathrm{O}$. Hence, PAN was strongly removed by pathways in addition to stomatal openings.

The smallest values of $R_{c}$ for PAN occur during mid afternoon in September and early October but tend to shift to mid morning with a concomitant increase in $R_{c}$ during mid afternoon later in October and on November 1. This shift corresponds to the shift of photosynthetic activity typically observed when vegetation is under stress, which in this case was probably related to cold nighttime conditions. Frosts began to occur about October 8 . During the second half of October, the vegetation was becoming less active physiologically; it was predominantly brown by November 1 . The values of $\mathrm{R}_{c}$ for $\mathrm{H}_{2} \mathrm{O}$ were then near $2.3 \mathrm{~s} \mathrm{~cm}^{-1}$ during sunny conditions, most likely as a result of evaporation from the soil surface. Despite these surface conditions, $R_{c}$ for PAN is still not very large, indicating that uptake by leaf and soil surfaces can be rapid even without actively growing vegetation.

Very small values of $R_{c}$ for PAN were frequently observed during sunny conditions. If we assume that emission of PAN did not take place, negative values for $R_{c}$ in Table 1 indicate extreme cases and have no physical significance except that the removal resistance in the bulk canopy was near zero. This concurrence of small $R_{c}$ values and sunny conditions supports the suggestion by Taylor et al. (1961) that the uptake of PAN through leaf stomata is strongly affected 
TABLE 1. Summary of selected data.

$\begin{array}{lllllllll}\text { Period Solar Flux } & \lambda E & H & u_{*} & T_{s} & v_{d} & R_{a}+R_{b} & R_{c} & H_{2} O R_{c}\end{array}$

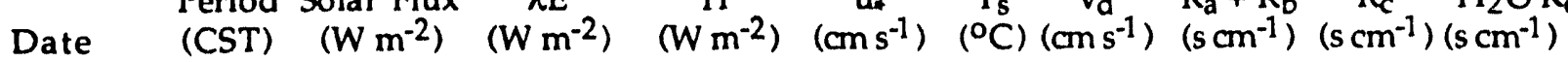

\begin{tabular}{|c|c|c|c|c|c|c|c|c|c|c|}
\hline \multirow[t]{2}{*}{20 Sept. } & $1230-1330$ & 712 & 287 & 152 & 30 & 25 & 1.57 & 0.50 & 0.14 & 0.50 \\
\hline & $1530-1630$ & 257 & 133 & 13 & 22 & 21 & 0.27 & 0.76 & 2.93 & 1.20 \\
\hline \multirow[t]{7}{*}{27 Sept. } & 0915-1015 & 657 & 282 & 137 & 23 & 27 & 1.08 & 0.61 & 0.32 & 0.85 \\
\hline & $1015-1115$ & 744 & 336 & 141 & 24 & 29 & 0.62 & 0.61 & 1.01 & 0.91 \\
\hline & $1115-1215$ & 765 & 386 & 110 & 23 & 29 & 1.67 & 0.63 & $(-0.03)$ & 0.84 \\
\hline & $1215-1315$ & 713 & 366 & 75 & 24 & 29 & 3.00 & 0.63 & $(-0.29)$ & 0.92 \\
\hline & $1315-1415$ & 615 & 332 & 59 & 26 & 29 & 1.93 & 0.61 & $(-0.09)$ & 1.10 \\
\hline & $1415-1515$ & 455 & 254 & 19 & 20 & 28 & 0.83 & 0.78 & 0.42 & 1.24 \\
\hline & $1515-1615$ & 274 & 147 & -3 & 13 & 27 & 0.33 & 1.23 & 1.79 & 1.80 \\
\hline \multirow[t]{3}{*}{2 Oct. } & $1200-1300$ & 714 & 299 & 141 & 40 & 25 & 1.90 & 0.40 & 0.12 & 1.12 \\
\hline & $1300-1400$ & 625 & 283 & 115 & 43 & 25 & 1.18 & 0.39 & 0.46 & 1.22 \\
\hline & $1400-1500$ & 479 & 258 & 34 & 37 & 23 & 0.66 & 0.45 & 1.06 & 1.16 \\
\hline \multirow[t]{4}{*}{11 Oct. } & $1230-1330$ & 644 & 186 & 202 & 21 & 21 & 1.86 & 0.63 & $(-0.09)$ & 1.41 \\
\hline & $1330-1430$ & 525 & 161 & 162 & 22 & 20 & 1.32 & 0.62 & 0.13 & 1.54 \\
\hline & $1430-1530$ & 359 & 108 & 96 & 23 & 18 & 1.06 & 0.65 & 0.29 & 1.94 \\
\hline & $1530-1630$ & 152 & 61 & 8 & 19 & 14 & 0.51 & 0.87 & 1.09 & 2.21 \\
\hline \multirow[t]{6}{*}{12 Oct. } & 0915-1045 & 625 & 162 & 238 & 21 & 21 & 1.62 & 0.61 & 0.01 & 1.69 \\
\hline & $1045-1245$ & 688 & 210 & 240 & 24 & 23 & 0.70 & 0.57 & 0.87 & 1.38 \\
\hline & $1245-1345$ & 593 & 179 & 84 & 25 & 22 & 0.73 & 0.57 & 0.81 & 1.54 \\
\hline & $1345-1445$ & 456 & 150 & 129 & 19 & 22 & 0.78 & 0.71 & 0.58 & 1.73 \\
\hline & $1445-1545$ & 283 & 104 & 55 & 16 & 19 & 0.33 & 0.87 & 2.13 & 1.91 \\
\hline & $1545-1645$ & 107 & 33. & -1 & 7 & 15 & 0.19 & 2.16 & 3.02 & 3.18 \\
\hline \multirow[t]{6}{*}{17 Oct. } & 0945-1045 & 610 & 241 & 15 & 69 & 25 & 3.59 & 0.25 & 0.03 & 1.07 \\
\hline & $1045-1145$ & 495 & 240 & 65 & 69 & 25 & 2.36 & 0.25 & 0.17 & 1.03 \\
\hline & $1145-1245$ & 502 & 259 & 54 & 76 & 25 & 1.84 & 0.23 & 0.32 & 1.01 \\
\hline & $1245-1345$ & 313 & 212 & -33 & 78 & 23 & 0.74 & 0.22 & 1.13 & 1.03 \\
\hline & 1345-1445 & 200 & 212 & -95 & 73 & 22 & 0.35 & 0.24 & 2.59 & 0.79 \\
\hline & $1445-1545$ & 9 & 81 & -56 & 68 & 22 & 0.15 & 0.25 & 6.20 & 2.42 \\
\hline \multirow[t]{4}{*}{22 Oct. } & 1245-1345 & 540 & 120 & 201 & 25 & 18 & 0.19 & 0.56 & 4.80 & 2.07 \\
\hline & $1345-1445$ & 407 & 96 & 145 & 21 & 17 & 0.31 & 0.65 & 2.59 & 2.38 \\
\hline & $1445-1545$ & 235 & 62 & 57 & 18 & 14 & 0.17 & 0.81 & 5.22 & 2.71 \\
\hline & $1545-1615$ & 105 & 25 & 2 & 11 & 11 & 0.19 & 1.50 & 3.82 & 4.84 \\
\hline \multirow[t]{4}{*}{23 Oct. } & $1030-1130$ & 637 & 138 & 263 & 33 & 20 & 1.42 & 0.45 & 0.25 & 2.07 \\
\hline & $1130-1230$ & 634 & 157 & 240 & 34 & 21 & 1.03 & 0.45 & 0.53 & 1.90 \\
\hline & $1230-1330$ & 533 & 128 & 181 & 38 & 20 & 0.28 & 0.42 & 3.09 & 2.20 \\
\hline & $1330-1430$ & 191 & 73 & 30 & 31 & 16 & 0.39 & 0.54 & 2.00 & 2.62 \\
\hline \multirow[t]{3}{*}{24 Oct. } & $1115-1215$ & 586 & 144 & 247 & 35 & 18 & 2.62 & 0.44 & $(-0.06)$ & 1.59 \\
\hline & $1215-1515$ & 414 & 106 & 144 & 35 & 16 & 0.23 & 0.46 & 3.82 & 1.87 \\
\hline & $1515-1745$ & 55 & 24 & -12 & 20 & 9 & 0.09 & 0.91 & 9.82 & 4.69 \\
\hline \multirow[t]{4}{*}{1 Nov. } & $1015-1315$ & 496 & 136 & 157 & 45 & 24 & 0.77 & 0.36 & 0.93 & 2.35 \\
\hline & 1315-1515 & 220 & 104 & 1 & 47 & 22 & 0.06 & 0.37 & 15.10 & 2.29 \\
\hline & $1615-1715$ & 16 & 15 & -46 & 34 & 18 & 0.11 & 0.52 & 8.29 & 11.86 \\
\hline & 1745-1915 & 0 & 14 & -43 & 34 & 16 & $(-0.07)$ & 0.53 & -- & 11.70 \\
\hline
\end{tabular}


by photosynthetic activity. Mudd (1975) suggested that proteins in leaves would be most susceptible to reactions with PAN when the leaves are illuminated and photosynthesis has been occurring. Because of the likely high solubility of PAN in lipids (Gaffney et al., 1987), another pathway to proteins within the interior of leaves in addition to the more direct route through the stomatal openings could be across the waxy leaf cuticle.

\section{CONCLUSIONS}

The rapid uptake of PAN by vegetation observed in this study indicates that the deposition velocities for PAN that are currently used in various models (e.g., Wesely, 1989) are significantly underestimated. The most rapid uptake, indicating almost a zero bulk surface resistance, seems to occur for green vegetation during sunny conditions, which supports the hypothesis that PAN is highly reactive with photosynthetic products in leaves. PAN uptake at the surface, however, appears to have several pathways other than through leaf stomata, and uptake by soil and senescent vegetation could conceivably also be fairly large as indicated by data obtained in the present experiments. Variability in the observational data however, preclude strong conclusions on the mechanisms that control PAN uptake.

\section{ACKNOWLEDGMENTS}

We thank Dr. Fred W. Breitbeil, III, of DePaul University for his assistance with instrument calibration for PAN analysis. This work was supported by the U.S. Department of Energy under Contract No. W-31-109-Eng-38 as part of the Atmospheric Chemistry Program of the Office of Energy Research, Office of Health and Environmental Research.

\section{REFERENCES}

Brutsaert, W., 1982: Evaporation into the Atmosphere. D. Reidel Publishing Company, Dordrecht, 299 pp.

Gaffney, J. S., G. E. Streit, W. D. Spall, and J. H. Hall, 1987: Beyond acid rain. Environ. Sci. Technol., 21, 519-524.
Gaffney, J. S., N. A. Marley, and E. W. Prestbo, 1989: Peroxyacyl nitrates (PANs): Their physical and chemical properties. The Handbook of Environmental Chemistry, Volume $4 /$ Part B, O. Hutzinger, Ed., Springer-Verlag, Berlin, 1-38.

Garland, J. A., 1977: The dry deposition of sulphur dioxide to land and water surfaces. Proc. Roy. Soc. Lond., 12, 245-268.

Garland, J. A., and S. A. Penkett, 1976: Absorption of peroxy acetyl nitrate and ozone by natural surfaces. Atmus. Environ., 10, 1127-1131.

Hill, A. C., 1971: Vegetation: A sink for atmospheric pollutants. J. Air Pollut. Control Assoc., 21, 341-346.

Mudd, J. D., 1975: Peroxyacyl nitrates. Responses of Plants to Air Pollution, J. B. Mudd and T. T. Kozlowski, Eds., Academic Press, New York, 97118.

Shepson, P. B., J. W. Bottenheim, D. R. Hastie, and A. Venkatram, 1992: Determination of the relative ozone and PAN deposition velocities at night. Geophys. Res. Let., 19, 1121-1124.

Singh, H. B., 1987: Reactive nitrogen in the troposphere. Environ. Sci. Technol., 21, 320-327.

Taylor, O. C., W. M. Dugger, jr., E. A. Cardiff, and E. F. Darley, 1961: Interaction of light and atmospheric photochemical products ('smog') within plants. Nature, 192, 814-816.

Wesely, M. L., and B. B. Hicks, 1976: Some factors that affect the deposition rates of sulfur dioxide and similar gases on vegetation. J. Air Pollut Control Assoc., 27, 1110-1116.

Wesely, M. L., 1989: Parameterization of surface resistances to gaseous dry deposition in regionalscale numerical models. Atmos. Environ., 23, 1293-1304.

Wesely, M. L., D. H. Lenschow, and O. T. Denmead, 1989: Flux measurement techniques. Global Tropospheric Chemistry, Chemical Fluxes in the Global Atmosphere, NCAR Report, D. H. Lenschow and B. B. Hicks, Eds., National Center for Atmospheric Research, Boulder, Colo., $31-46$. 

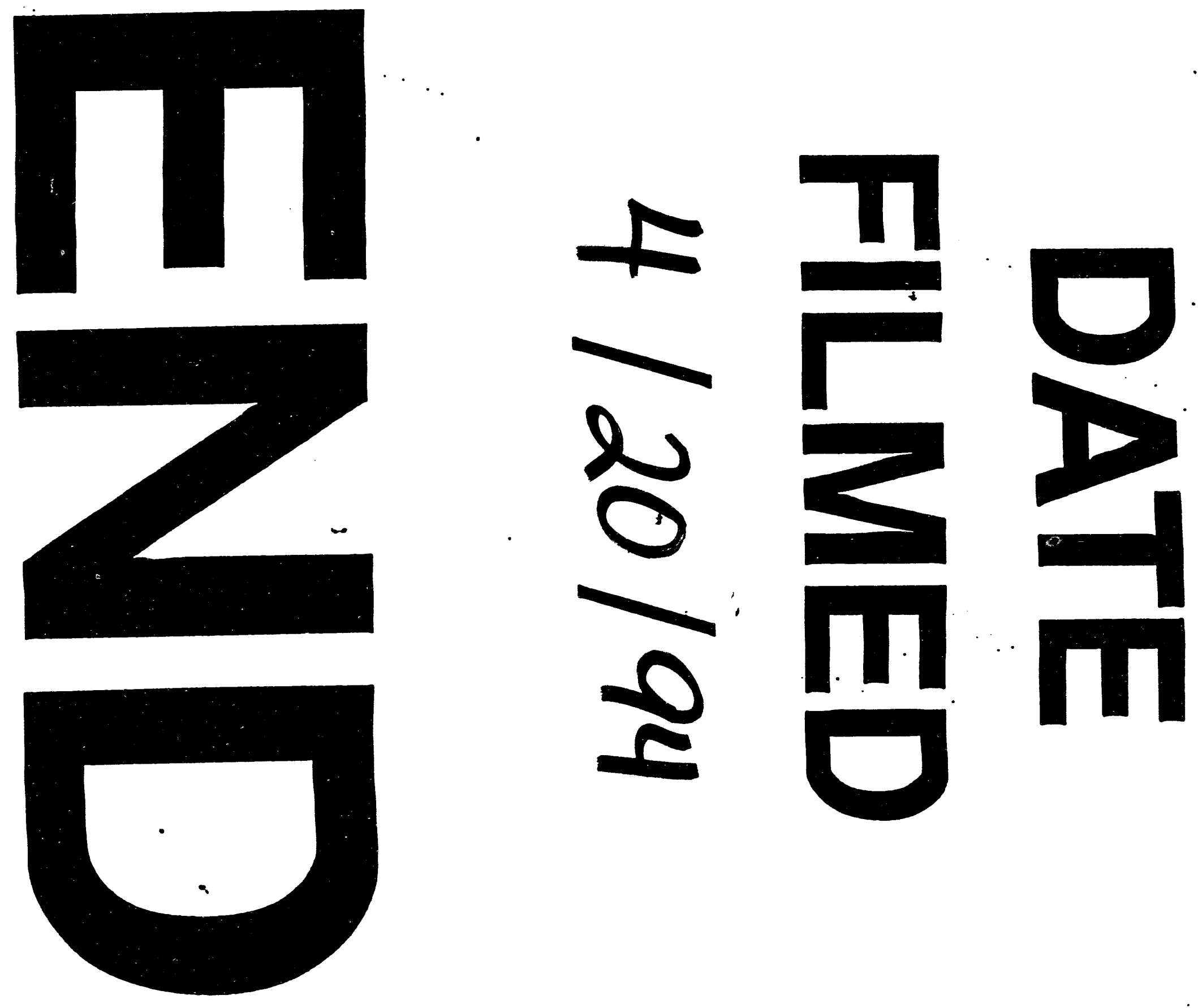


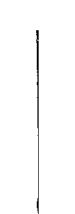

